\title{
RESEARCH ON THE CORROSION BEHAVIOR OF THE STAINLESS-STEEL THIN FILMS COATED BY PVD METHOD, MAGNETRON ASSISTED
}

\author{
Simona BOICIUC \\ "Dunarea de Jos" University of Galati, Romania \\ e-mail: simonaboiciuc@yahoo.com
}

\begin{abstract}
The paper follows the corrosion behaviour of X10CrNi 18-8 stainless steel thin films coated by PVD method, magnetron assisted, on glass and copper substrates. It was found that with the increase of the coating time increases of the thickness of the coated layer which leads to the decrease of the corrosion rate. The surface condition can influence the corrosion behaviour through the existing defects and the size of the roughness. Coating uniformity, respectively corrosion, changes with the distance from the axis of symmetry of the magnetron.
\end{abstract}

KEYWORDS: d.c. magnetron, stainless steel deposition

\section{Introduction}

PVD coatings have multiple applications that can be used as biocompatible materials, for protection against corrosion, erosion having, on the one hand, good properties of wear resistance, mechanical resistance, hardness, good adhesion, resistance to oxidation and temperature and, on the other hand, good optical, electrical, magnetic properties. Due to these properties, PVD coatings can be an alternative to conventional surface treatments, presenting a lowcost price, under the conditions of using nonpolluting installations, respectively technologies [1].

Depending on the coating parameters used, the microstructure of the films obtained by the PVD method can vary from a porous columnar shape to a compact columnar one, and can also reach shapes with equiaxial grains with a high degree of compactness (the increase of the temperature favours the phenomena of recrystallization leading to the obtaining polyhedral grains) [2, 3]. In the case of films that require good corrosion and wear behaviour, it is necessary to obtain a structure as compact as possible (aspect favoured by low pressure coatings) [3].

The surface may contain pores or cracks which may affect corrosion resistance. However, this does not only depend on the degree of porosity resulted and the existing structural defects, but also depends on other factors such as chemistry of coatingsubstrate interface, coating adhesion, structure, surface/substrate defect density, film/substrate roughness, film uniformity and residual stresses.

One of the factors that influence the structure, adhesion, film roughness and residual stresses is the substrate temperature. It is well known that low temperature coatings impede the mobility of atoms to migrate on the surface of the substrate, leading to the formation of high residual stresses. The roughness of the film decreases with increasing substrate temperature [3].

The problems that arise in the case of thin film corrosion are due to the penetration of the corrosive agents by these defects and their reaching the substrate.

Thus, it becomes important to determine the origin of these defects and how they develop on the surface. A number of defects specific to PVD coatings are: shallow conical structures (droplets), acicular holes with dimensions of the order of micrometres and large but not deep craters, with dimensions between 10-40 $\mu \mathrm{m}$ [4]. The defects of conical shape have a quite high incidence and develop in the layer during its growth. Their appearance is due either to the presence of foreign particles with which the layer comes in contact (dust) or to the metal droplets in the target (from the vacuum chamber). Usually the region under the cone is not completely filled with material [4].

The needle holes defects extend throughout the entire coating and originate from surface defects (a small hole in the substrate) or can be caused by corrosion products (wet cleaning) or dust particles 
that have not been removed from the surface of the substrate during the coating process. The high roughness of the substrates used could have the same effect. The PVD method has a poor ability to cover these defects (due to the shadow effect) [4].

The origin of large but not deep craters could be explained by the presence of particles that appeared immediately after the coating began (corrosion products resulting from wet cleaning, dust particles) [4].

Regarding the methods of processing the surface of the substrate, they must take into account its cleaning and activation, respectively the creation of a clean surface from a chemical point of view (by removing the impurities and gases adsorbed on the surface) and making stable and strong physicalchemical connections between the substrate and the coated material.

The applications of thin films with anticorrosive properties are: in the aerospace industry, in the automotive industry, to reduce their weight and implicitly to reduce the fuel consumption, in the electronic industry, to the coating of thin films anticorrosive on the objects of art and architecture obtained from brass or bronzes.

In recent years, many efforts have been made to develop new anticorrosive coatings through PVD methods. Thus, the stainless-steel coating has become more and more interesting and studied.

The austenitic stainless steels were initially designed to make the necessary equipment for home use and interior decoration, and then to expand their use in fields such as the food industry, chemical, petrochemical, energy and medical industries when developing medical prostheses, orthopaedic implants, endodontic instruments and dental implants. The means of land, naval, air, space transport also include component parts made of materials coated with stainless steel that have good mechanical strength as well as resistance to aggressive environments and atmospheres.

The content of more than $12 \% \mathrm{Cr}$ gives the steel the property to cover with a passive layer in most environments (air, water, acids, industrial atmosphere etc.), making them resistant to oxidation and corrosion, in relation to other metallic materials. As a rule, corrosion resistance increases with increasing of chromium content. The passive layer is mainly composed of chromium oxides (formed in the presence of oxygen), is adherent, dense, impermeable and slightly soluble, which makes it resistant to the action of a large number of aggressive environments. It has been observed the erosion resistance, practically unlimited, of austenitic stainless steels compared to the low corrosion resistance of copper in which the corrosion products are fragile and easy to shear [5].
The use of stainless steels in the medical industry is due to both good mechanical resistance properties, physical, chemical properties, and good biocompatibility, respectively, good corrosion resistance to biological fluids.

However, stainless steels are liable to corrosion (in saline environment) compared to titanium alloys, releasing metal ions $\left(\mathrm{Ni}^{2+}, \mathrm{Cr}^{3+}, \mathrm{Cr}^{6+}\right)$ into the body that can cause allergic, inflammatory reactions (Speide and Uggowitzer, 1998). For this reason, stainless steels are used only for temporary medical implants such as fixing screws and orthopaedic rods for fracture fixation [6].

The purpose of the paper is to study the corrosion behaviour in salt mist of thin films of $\mathrm{X} 10 \mathrm{CrNi} 18-8$ stainless steel and their microstructural characterization.

\section{Experimental conditions}

To obtain the films, a circular austenitic stainless-steel plate X10CrNi 18-8 with a diameter of $46.5 \mathrm{~mm}$ and a thickness of $1 \mathrm{~mm}$ was used as target.

The substrate material consisted of glass plates with dimensions $76 \times 25 \times 1 \mathrm{~mm}$ and copper plates with dimensions of $80 \times 20 \times 1 \mathrm{~mm}$.

The films were obtained using a PVD spray coating machine, consisting of a vacuum chamber with a capacity of 2 litters, a planar magnetron with ferrite magnets $(\phi 40 \times 22 \times 9)$ neodymium $(\phi 15 \times 8)$, a vacuum pump with sliding blades, a variable source of DC voltage from 100 to 600 volts.

The machine allows the variation of the magnetron substrate spacing between 25 and $90 \mathrm{~mm}$, and the substrate temperature can be monitored with a chromel-alumel thermocouple.

The atmosphere used to maintain the plasma during coating process was the rarefied argon in a pressure range between $3 \cdot 10^{-2}-8 \cdot 10^{-3}$ mbar. The argon flow used was $100 \mathrm{~cm}^{3} / \mathrm{min}$.

The stages of obtaining the coatings were the following:

a. Preparation of the substrate surface

b. Coating films by PVD method, magnetron assisted

a. Preparation of the substrate surface

This step consisted of: washing the plates with a special detergent, washing them with water, then with distilled water, ultrasonic cleaning with ethanol and then drying with compressed air.

b. Coating films by PVD method, magnetron assisted

The regimes used for coating stainless steel films are presented in Table 1. The samples P1 and P2 were obtained by coating stainless steel films on the glass substrate and P3 and P4 on the copper substrate. 
Table 1. Regimes for obtaining X10CrNi 18-8 steel films

\begin{tabular}{|c|c|c|c|c|c|c|}
\hline $\begin{array}{c}\text { Sample } \\
\text { code }\end{array}$ & $\begin{array}{c}\text { Voltage } \\
{[\mathrm{V}]}\end{array}$ & $\begin{array}{c}\text { Current } \\
{[\mathrm{mA}]}\end{array}$ & $\begin{array}{c}\text { Pressure } \\
{[\mathrm{mbar}]}\end{array}$ & $\begin{array}{c}\text { Substrate } \\
\text { temperature }\left[{ }^{\circ} \mathrm{C}\right]\end{array}$ & $\begin{array}{c}\text { Target - substrate } \\
\text { distance }[\mathrm{mm}]\end{array}$ & $\begin{array}{c}\text { Deposition } \\
\text { time [min] }\end{array}$ \\
\hline P1 & 545 & 55 & $2.5 \times 10^{-2}$ & 34 & 66 & 20 \\
\hline P2 & 545 & 55 & $2.5 \times 10^{-2}$ & 34 & 66 & 20 \\
\hline P3 & 550 & 55 & $2.5 \times 10^{-2}$ & 34 & 66 & 40 \\
\hline P4 & 550 & 55 & $2.5 \times 10^{-2}$ & 34 & 66 & 40 \\
\hline
\end{tabular}

\subsection{Microscopic characterization of the obtained films}

Microscopic analysis of the obtained films was performed using a Neophot 2 optical microscope with computerized data acquisition.

\subsection{Corrosion behaviour of the obtained films}

The corrosion behaviour of thin films in saline mist was studied using a corrosion chamber, provided with an automatic system for measuring and regulating the temperature, exhaust system of the used solution or of the condensation, obtained during the tests.

The samples were placed on plastic bars.

Accelerated corrosion test in saline mist was performed according to SRISO 9227.

To perform the test, the necessary solution was prepared, by dissolving in distilled water, with a conductivity less than or equal to $20 \mu \mathrm{S} / \mathrm{cm}^{2}$ la $35 \pm 2$ ${ }^{\circ} \mathrm{C}$, of a quantity of sodium chloride, to obtain a concentration of $50 \pm 5 \mathrm{~g} / \mathrm{L}$. The relative density of a solution with this concentration ranges from 1.00255 to 1.0400 .

The $\mathrm{pH}$ of the salt solution was adjusted so that the $\mathrm{pH}$ of the solution collected in the spray chamber to range between 6.5 and 7.2. It was measured with a

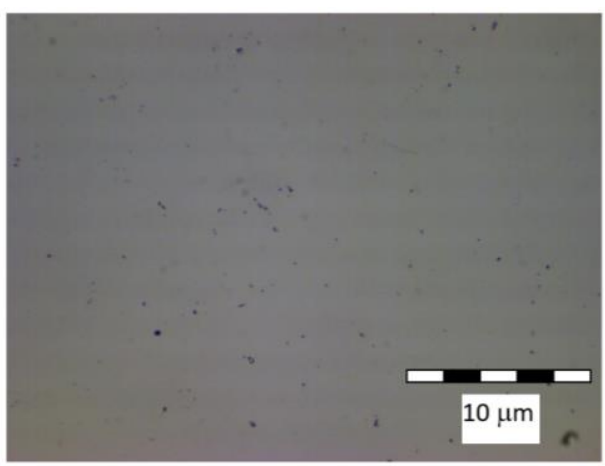

P1
pH meter HI 991001, produced by "Hanna Instruments", provided with a temperature indicator.

The corrosion test was performed for a period of 120 hours at $35{ }^{\circ} \mathrm{C}$. Initially the samples were degreased with alcohol, weighed on the analytical balance with an accuracy of $0.01 \mathrm{mg}$.

At an interval of 24 hours, the samples were removed from the chamber, the corrosion products were removed by washing with water and dried. Subsequently, the weighing on the analytical balance was carried out with an accuracy of $0.01 \mathrm{mg}$.

\section{Experimental results}

\subsection{Microscopic characterization of the obtained films}

Following microscopic analysis, it was observed that the obtained films of $\mathrm{X} 10 \mathrm{CrNi} 18-8$ stainless steel show no cracks, are relatively homogeneous and adherent as can be seen in Fig. 1. The samples deposited on glass substrate have a mirror surface and show a series of imperfections from the vacuum chamber and those deposited on a copper substrate are matte and have a surface whose roughness is consistent with that of the substrate.

The roughness of the copper substrate was $\mathrm{Ra}=$ $0.21 \mu \mathrm{m}$ and after the film coating it reached $\mathrm{Ra}=$ $0.24 \mu \mathrm{m}$. To determine this parameter a NAMICON TR 100 device was used.

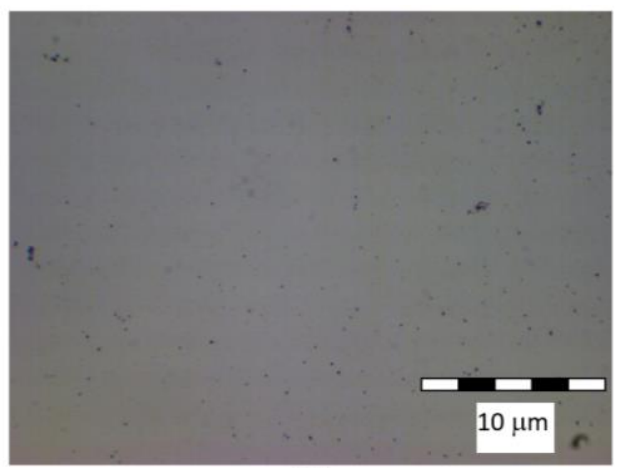

P2 


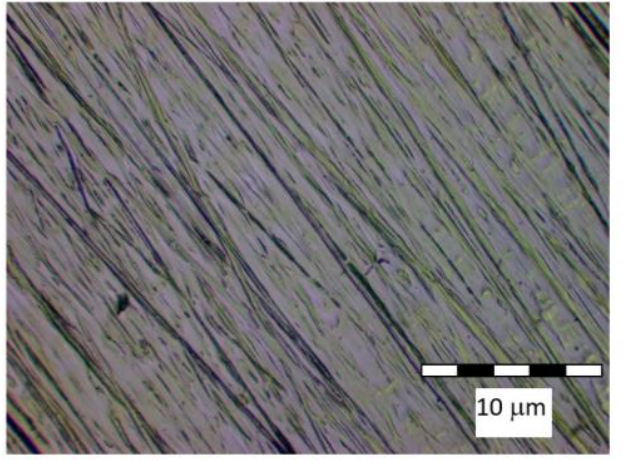

P3

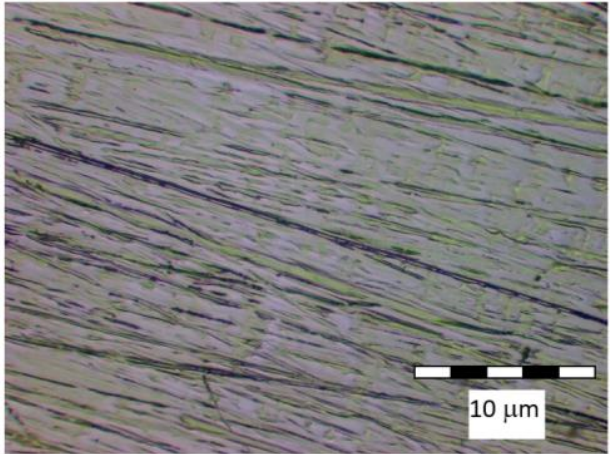

P4

Fig. 1. Image of films with different coating regimes

\subsection{Corrosion behaviour of the obtained films}

Following the corrosion test in saline mist, it was found that the films coated on glass substrate did not change after 120 hours. In the case of films coated on copper substrate, it was found that the best corrosion behaviour was noticed on sample P4 (with longer coating duration), aspects highlighted in Fig. 2 and Fig. 3. It can be observed that the roughness of the substrate influences the geometry of the surface of the coated film, respectively the appearance, concentration, corrosion on certain areas.
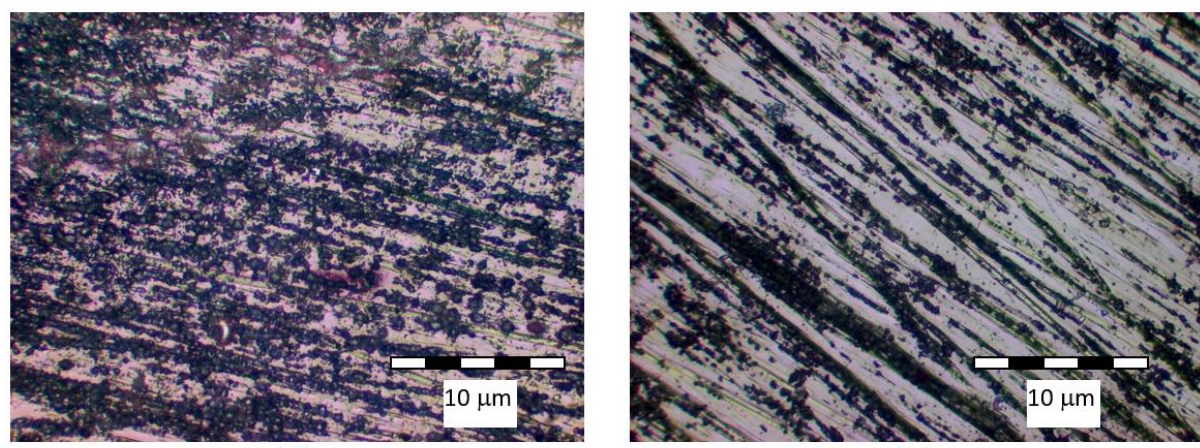

P3

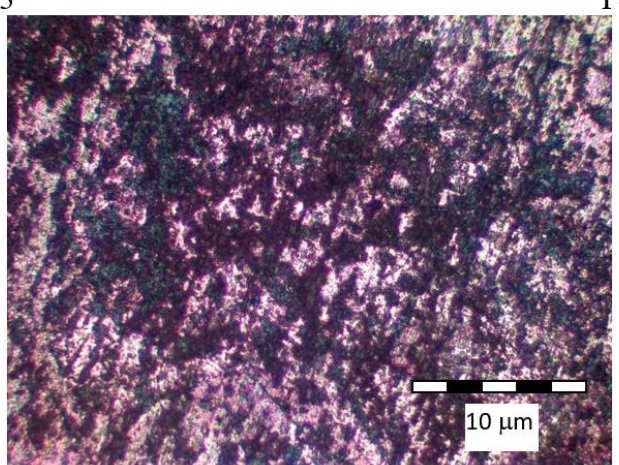

$\mathrm{Cu}$

Fig. 2. Image of films with different coating regimes, after corrosion

When analysing Fig. 2, it can be seen that the stainless-steel films coated on copper substrate are affected by corrosion in saline mist, a point corrosion (concentrated on surfaces of several $\mathrm{mm}^{2}$ ) quite deep. This is caused by the presence of chlorine ions which lead to the passage of the passive film from place to place.
The corrosion behaviour is increasingly better with the increase of the coated film thickness. Also, with increasing the coating time, the film thickness and grain size increase which leads to its roughness.

Another factor influencing the corrosion behaviour is the uniformity of the coated film. This decreases with increasing distance from the axis of 


\section{THE ANNALS OF "DUNAREA DE JOS” UNIVERSITY OF GALATI \\ FASCICLE IX. METALLURGY AND MATERIALS SCIENCE \\ No. 4 - 2018, ISSN 2668-4748; e-ISSN 2668-4756 \\ Article DOI: https://doi.org/10.35219/mms.2018.4.08}

symmetry of the magnetron, which makes the corrosion velocity different (the areas further away

from the axis have more pronounced corrosion).

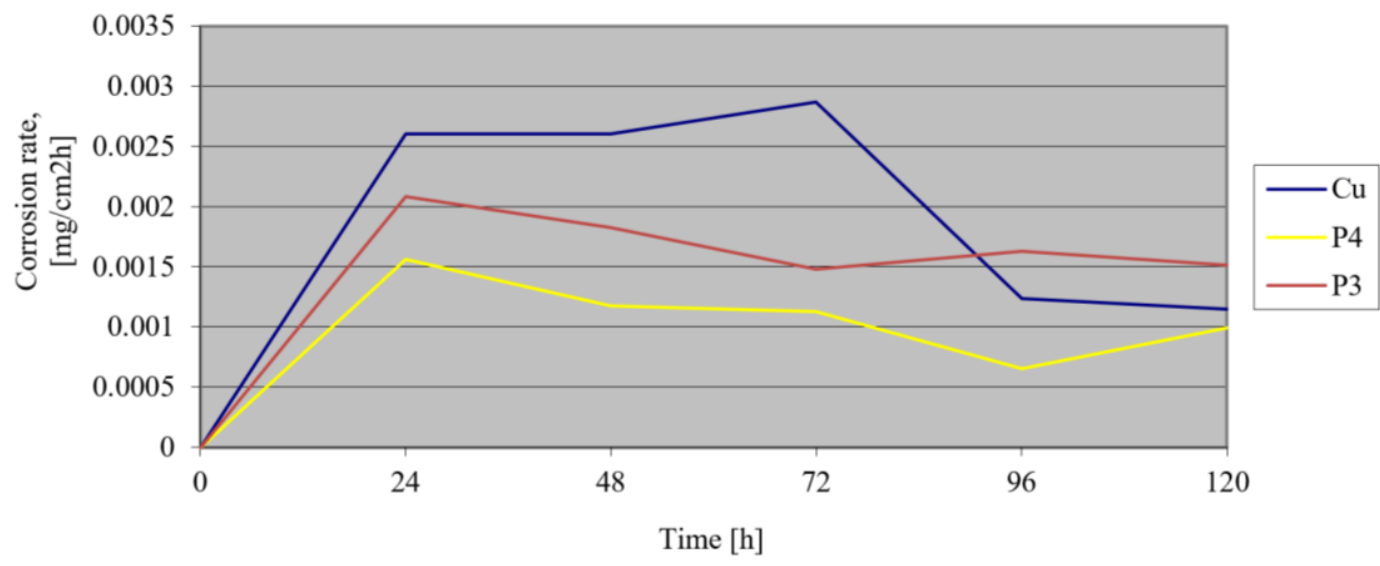

Fig. 3. Corrosion behaviour of the coated films

\section{Conclusions}

The corrosion behaviour of thin films is influenced by the state of the surface, respectively by the surface defects and roughness. The defects can be due to either a poor preparation of the substrate during its cleaning and activation or due to the impurification of the film in the vacuum chamber (droplets of target metal, dust). Corrosion occurs by penetrating corrosion solutions through these defects and attacking the substrate material.

The roughness of the coated film is influenced by the roughness of the substrate material and the coating conditions. The roughness of the substrate material depends on the preparation method. This should ensure a reduced surface roughness.

As the coating time increases, the film thickness and grain size increase which leads to its roughness.

The corrosion behaviour of stainless-steel films in saline mist revealed that the corrosion decreases with the increase of the coated film thickness.

On the other hand, the behaviour is influenced by the uniformity of the coated film. This decreases with increasing distance from the axis of symmetry of the magnetron, which causes a relatively uneven corrosion of the film.

The method represents an efficient alternative to the classic technologies for surface protection against corrosion, realized with a reduced consumption of materials and with a minor impact on the environment.

\section{References}

[1]. Viorica Muşat, Filme subţiri multifuncţionale, Editura CERMI Iași, 20, p. 33-59, 2005.

[2]. Thornton J. A., The microstructure of sputter-deposited coatings, Journal of Vacuum Science \& Technology A: Vacuum, Surfaces, and Films, vol. 4, p. 3059-3065, 1986.

[3]. Robert-A. Pato, Straturi subtiri multifunctionale de nitrura de titan, Teza de doctorat, Universitatea Tehnica Cluj Napoca, 2011.

[4]. Darja Kek Merl, Ingrid Milosev, Peter Panjan, Franc Zupanic, Morphology and corrosion properties $\mathrm{PVD} C r-\mathrm{N}$ coatings deposited on aluminium alloys, MTAEC9, 45(6), 593, Materiali in technologije, ISSN 1580-2949, 2011.

[5]. Levcovici M. S., Vasilescu E., Gheorghieș L. ş.a., Ingineria suprafeţelor, EDP Bucureşti, 2003.

[6]. Vasilescu V., Vasilescu E., Physical-Mechanical and Technological Characteristics of TilOZr Alloy for Dental Applications, The Annals of "Dunarea de Jos" University of Galati, Fascicle IX, Faculty of Metalurgy and Materials Science, no. 3, ISSN 1453-083X, 2016 